\title{
INIERE-SPACQE
}

\section{EXPANSÃO DO CAPITAL E AÇÕES DOS ESTADOS NACIONAIS NA GRAN AMAZONÍA (2000-2019): impactos e impasses}

\section{CAPITAL EXPANSION AND ACTIONS BY NATIONAL STATES IN THE GRAND AMAZONIA (2000-2019): impacts and impasses}

\section{EXPANSIÓN DE CAPITAL Y ACCIONES DE LOS ESTADOS NACIONALES EN LA GRAN AMAZONÍA (2000-2019): impactos e impasses}

\section{Thais Virga}

Doutora pelo Programa de Pós-Graduação em Desenvolvimento Econômico da Universidade Estadual de Campinas - CEDE/UNICAMP. Pós-Doutoranda no Programa de Pós-Graduação em Geografia Humana (PPGH/ FFLCH) da Universidade de São Paulo - PPGH/FFLCH/USP. thaisvirga@gmail.com / http://orcid.org/0000-0002-4221-3659

\section{Humberto Miranda do Nascimento}

Doutor em Economia Aplicada pela Universidade Estadual de Campinas - UNICAMP. Professor do Programa de Pós-Graduação em Desenvolvimento Econômico e Pesquisador do Centro de Estudos de Desenvolvimento Econômico (CEDE) do Instituto de Economia da Universidade Estadual de Campinas - IE/UNICAMP. humbertomnascimento@gmail.com / htttp://orcid.org/0000-0001-5658-2909

Recebido: 07/06/2020; Aprovado: 04/01/2021; Publicado: 25/03/2021.

\section{RESUMO}

A emergência da China como ator econômico global no limiar do século XXI impactou diretamente na consolidação e ampliação de novos e velhos centros de extração e produção agromineral em grande parte da América Latina. Objetiva-se, neste artigo, discutir sobre relevantes impactos dos investimentos chineses na Gran Amazonia no período 2000-2019 e mostrar como os Estados nacionais sul-americanos contribuíram para incrementar as frentes de expansão neste imenso espaço subcontinental. Como metodologia, apresenta-se o levantamento mais recente sobre as principais frentes de expansão do capital nos países da Gran Amazonía, com base em dados de pesquisa de campo, consultas a instituições governamentais, não governamentais, empresariais e outras organizações civis, além de bibliografia atualizada. Conclui-se que a expansão do capital chinês sobre toda a Gran Amaronía foi produto de uma relação consensual com os Estados Nacionais, gerando oportunidades econômicas, porém, com importantes implicações socioambientais.

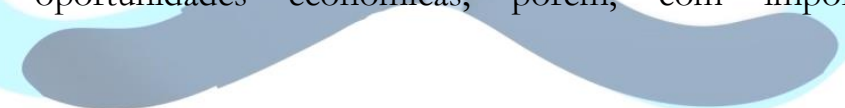

Palavras-chave: Expansão do Capital (China); Gran Amazonía; Ação dos Países Sul-americanos.

\begin{abstract}
The emergence of China as a global economic actor on the threshold of the 21st century had a direct impact on the consolidation and expansion of new and old centers of extraction and agromineral production in much of Latin America. The aim of this article is to discuss the relevant impacts of Chinese investments in Gran Amazonía in the period 2000-2019 and to show how the South American national states contributed to the expansion fronts in this immense subcontinental space. As a methodology, the most recent survey on the main fronts of capital expansion in the countries of Gran Amazonía is presented, based on data from field research, consultations with governmental, non-governmental, business and other civil organizations, in addition to updated
\end{abstract}


| Expansão do capital e ações dos Estados Nacionais na Gran Amazonía (2000-2019): impactos e impasses |

\section{|Thais Virga | Humberto Miranda do Nascimento |}

bibliography. It is concluded that the expansion of Chinese capital over the whole of Gran Amazonía was the product of a consensual relationship with the National States, generating economic opportunities, however, with important socio-environmental implications.

Keywords: Capital Expansion (China); Gran Amazonía; Action by South American Countries.

\section{RESUMEN}

El surgimiento de China como actor económico global en el umbral del siglo XXI tuvo un impacto directo en la consolidación y expansión de nuevos y viejos centros de extracción y producción agromineral en gran parte de América Latina. El objetivo de este artículo es discutir los impactos relevantes de las inversiones chinas en la Gran Amazonía en el período 2000-2019 y mostrar cómo los estados nacionales sudamericanos contribuyeron a los frentes de expansión en este inmenso espacio subcontinental. Como metodología se presenta la encuesta más reciente sobre los principales frentes de expansión de capital en los países de la Gran Amazonía, con base en datos de investigaciones de campo, consultas con organizaciones gubernamentales, no gubernamentales, empresariales y otras organizaciones civiles, además de bibliografía actualizada. Se concluye que la expansión del capital chino por toda la Gran Amazonía fue producto de una relación consensuada con los Estados Nacionales, generando oportunidades económicas, sin embargo, con importantes implicaciones socioambientales.

Palabras clave: Expansión de Capital (China); Gran Amazonía; Acción de Países Sudamericanos.

\section{INTRODUÇÃO}

A Gran Amazonia é a expressão continental da maior porção dos territórios amazônicos nacionais presente em oito países da América do Sul - Bolívia, Brasil, Colômbia, Equador, Guiana, Peru, Suriname e Venezuela, além do departamento ultramarino da França (a Guiana Francesa). Segundo o IMAZON (2015), conta com uma

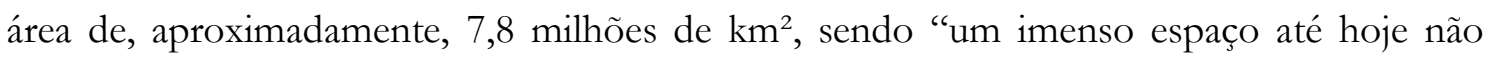
plenamente conhecido nem integrado nos respectivos territórios nacionais" (BECKER, 2010, p. 26). Ou, poder-se-ia dizer, pouco integrado para dentro e muito visado para fora, dada a importância estratégica de seus recursos naturais e da relevância de sua diversidade ecológica e étnico-cultural.

Do ponto de vista dos seus recursos naturais, após a emergência da China como ator econômico global no limiar do século XXI, a Gran Amaz̧onía viu consolidar-se em seus territórios novos centros de extração/produção agromineral, especialmente durante o período denominado de superciclo de preços das commodities (2003-2011)². Importantes áreas dos territórios amazônicos nacionais da América do Sul tornaram-se destino para os investimentos chineses nos setores extrativistas e agrominerais, além de avançar aos segmentos infraestruturais, sobretudo, aqueles ligados à energia e aos transportes.

\footnotetext{
${ }^{1}$ São comuns na literatura acadêmica o uso dos termos Amazônia Transnacional, Amazônia Sul-Americana, Pan-Amazônia ou Amazônia para se referir à mesma região. Adotamos a denominação espanhola Gran Amazonía para realçar sua dimensão continental e sua presença em diferentes nacionalidades.

${ }^{2}$ Sobre o "boom de commodities", ver Campello e Zucco (2015).
} 
| Expansão do capital e ações dos Estados Nacionais na Gran Amazonía (2000-2019): impactos e impasses |

\section{|Thais Virga | Humberto Miranda do Nascimento |}

Neste período, a realidade latino-americana vinha mudando, com a potência asiática tendo um papel de destaque, sobretudo, no incremento da inter-relação de grande parcela de sua produção econômica com o crescimento da demanda externa. E na América do Sul, a Gran Amazonía veio ganhando destaque como a nova "bola da vez" para satisfazer o voraz apetite do crescimento econômico chinês por produtos primários, mas não só dele. Lembremos que os interesses militares norte-americanos e energéticos russos em países amazônicos (como, por exemplo, e nessa ordem, na Colômbia e Venezuela), também reacenderam as disputas entre as superpotências por porções dos territórios amazônicos.

É de conhecimento corrente que a Gran Amazonía possui seus próprios antagonismos internos, decorrentes da insatisfação de demandas históricas de suas populações e diante das múltiplas potencialidades que apresenta - sejam naturais ou econômicas, culturais ou sociais, ou mesmo, em termos de segurança e geopolítica regional. Porém, é, sobretudo, o problema da integração intrarregional que constitui seu maior desafio, haja vista os interesses econômicos internacionais e sanha dos países que ainda a tratam como uma reserva ou fronteira de recursos a conquistar e explorar.

O fato é que esse imenso espaço, mais do que em qualquer outro momento da sua história, está exposto à exploração desmedida e ameaçadora da expansão da mineração e da fronteira agropecuária em âmbito internacional e sujeita ao controle de recursos naturais e energéticos, sem que ocorram maiores aproveitamentos e/ou benefícios concretos ao âmbito intrarregional. Não se trata de um temor recente, mas permanente.

Diante desta nova realidade do capitalismo global, devido principalmente à escalada do crescimento chinês, a pressão por aquisições e investimentos nos setores agro-mineiroenergético e a disputa por projetos de infraestrutura necessários a escoá-los "para fora", por parte das grandes potências, vem promovendo frentes de expansão do capital em patamares ainda não vistos na região, marcando sua dinâmica geoeconômica no período atual.

Para melhor entender esse processo, este texto visa discutir os impactos desses investimentos sobre a Gran Amazonía no período 2000-2019, analisando a exequibilidade das novas relações da China neste espaço num momento em que estas atingem seu auge. Como os impactos socioespaciais e políticos obedecem ao fortalecimento das frentes de expansão do capital, pode-se constatar que muitas das porções nacionais de seu território passaram a testemunhar um complexo e multiescalar estágio de transformação.

Desse modo, considerando os oito países que a compõem e os capitais chineses presentes e prospectados através de investimentos na Gran Amazonía, admite-se a hipótese de que os Estados Nacionais influenciaram de forma decisiva nos resultados dos aportes 
| Expansão do capital e ações dos Estados Nacionais na Gran Amazonía (2000-2019): impactos e impasses |

|Thais Virga | Humberto Miranda do Nascimento |

realizados, elevando fortemente os impactos econômicos, sociais e ambientais em seus territórios amazônicos. Em outros termos, a estratégia e o avanço do capital chinês obteve não só o consentimento como um forte suporte estatal nestes países.

A seguir, detalha-se mais concretamente o avanço chinês na Gran Amažnía no período recente e a resposta dos Estados nacionais sul-americanos. Não se desconhece a relação e interesses de outros países, mas a China é o elemento novo do processo e que, ao mesmo tempo, dirige a atenção de outros países para esse imenso espaço.

\section{AS FRENTES DE EXPANSÃo DO CAPITAL: efeitos na Gran Amazonía}

Inicialmente, para mais rigor da análise, esclarece-se que a Gran Amazonía apresenta três limites principais: o biogeográfico, uma extensão correspondente às áreas de floresta; $\mathrm{O}$ hidrográfico, cuja extensão incorpora toda a Bacia Amazônica; e, o político-administrativo, que conforma distintos critérios fronteiriços legais de cada um dos países. De acordo com informações da Rede Amazônica de Informação Socioambiental Georreferenciada (RAISG), o Brasil, Peru, Colômbia e Bolívia são os maiores países amazônicos, perfazendo $86,7 \%$ da área total (Tabela 1).

Tabela 1 - Superfície da Gran Amazonía em $\mathrm{km}^{2}$ e percentual por país.

\begin{tabular}{l|ccc}
\hline \multirow{2}{*}{ PAÍSES } & \multicolumn{3}{c}{ GRAN AMAZONÍA } \\
\cline { 2 - 4 } & Milhares de km ${ }^{2}$ & \% da Área no País & \% na Gran Amazonía \\
\hline Brasil & $5.006,3$ & 58,8 & 64,3 \\
Peru & 782,8 & 60,9 & 10,1 \\
Colômbia & 483,1 & 42,4 & 6,2 \\
Bolívia & 475,3 & 43,3 & 6,1 \\
Venezuela & 453,9 & 49,5 & 5,8 \\
Guiana & 215 & 100,0 & 2,8 \\
Suriname & 163,8 & 100,0 & 2,1 \\
Equador & 116,6 & 46,9 & 1,5 \\
Guiana Francesa & 86,5 & 100 & 1,1 \\
\hline Total & $7.783,3$ & 100 \\
\hline \multicolumn{4}{c}{ Fonte: IMAZON (2015), com adaptações. }
\end{tabular}

Esta caracterização inicial permite duas constatações: a importância territorial da Amazônia Brasileira para o conjunto da Gran Amazonía e, sobretudo, a relevância territorial das Amazônias nacionais, ou seja, a porção amazônica presente em cada país. Cada uma destas porções é considerada aqui para que se compreenda o papel das estratégias nacionais sobre seus recursos e porque os países dispõem de suas Amazônias de diferentes formas, para atrair investimentos externos.

Também é necessário conhecer os impasses que, nas últimas décadas, têm agravado a situação da região. Tais impasses se devem à expansão desenfreada do agronegócio e da 
| Expansão do capital e ações dos Estados Nacionais na Gran Amazonía (2000-2019): impactos e impasses |

\section{|Thais Virga | Humberto Miranda do Nascimento |}

pecuária (vinculada à apropriação da renda fundiária), assim como das atividades relacionadas à mineração e às atividades ilegais (ligadas, sobretudo, à extração de minérios, madeireiras informais, além do tráfico de drogas), sem falar do desmatamento e das queimadas. Mas, em que medida eles decorrem das frentes de expansão do capital?

Atualmente, a expansão do capital pela Gran Amažnía ocorre em velocidade acelerada, a partir de diversos agentes do setor privado, sejam esses internos (locais, regionais, nacionais) ou externos (chineses, norte-americanos, europeus ou russos). Isso pode ser explicado pelo boom de preços das commodities ocorrido desde o início deste século. A Figura 1 e o Gráfico 1 dão uma ideia de como se comportaram os preços das principais commodities no período 2003-2015 e o desempenho comercial (exportações mais importações) da América Latina e Caribe (ALC) com a China no período 200-2018. É importante ressaltar a extensão e profundidade desse superciclo de elevação dos preços internacionais, tendo em vista mudanças estruturais que aconteceram ${ }^{3}$.

Figura 1 - Mundo: Evolução anual dos preços das commodities internacionais por agrupamentos, no período 2003 a 2015. $(2005=100)$

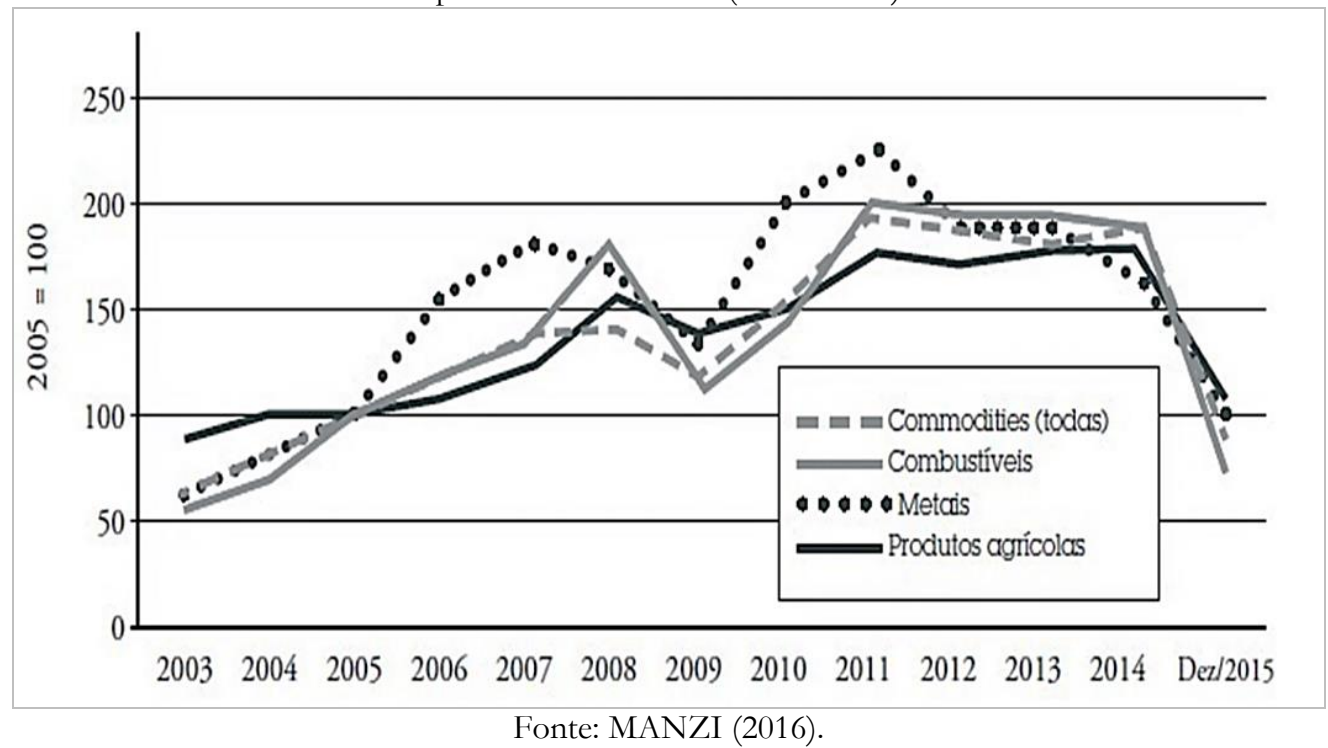

${ }^{3}$ Erten e Ocampo (2013) identificaram a existência de quatro superciclos, com variações de 30 a 40 anos, sendo três deles durante o crescimento econômico dos Estados Unidos a partir de 1894 aos anos 2000, e depois, com a ascensão da China. 
| Expansão do capital e ações dos Estados Nacionais na Gran Amazonía (2000-2019): impactos e impasses |

|Thais Virga | Humberto Miranda do Nascimento |

Gráfico 1 - Relação comercial da América Latina e Caribe com a China (2000-2018).

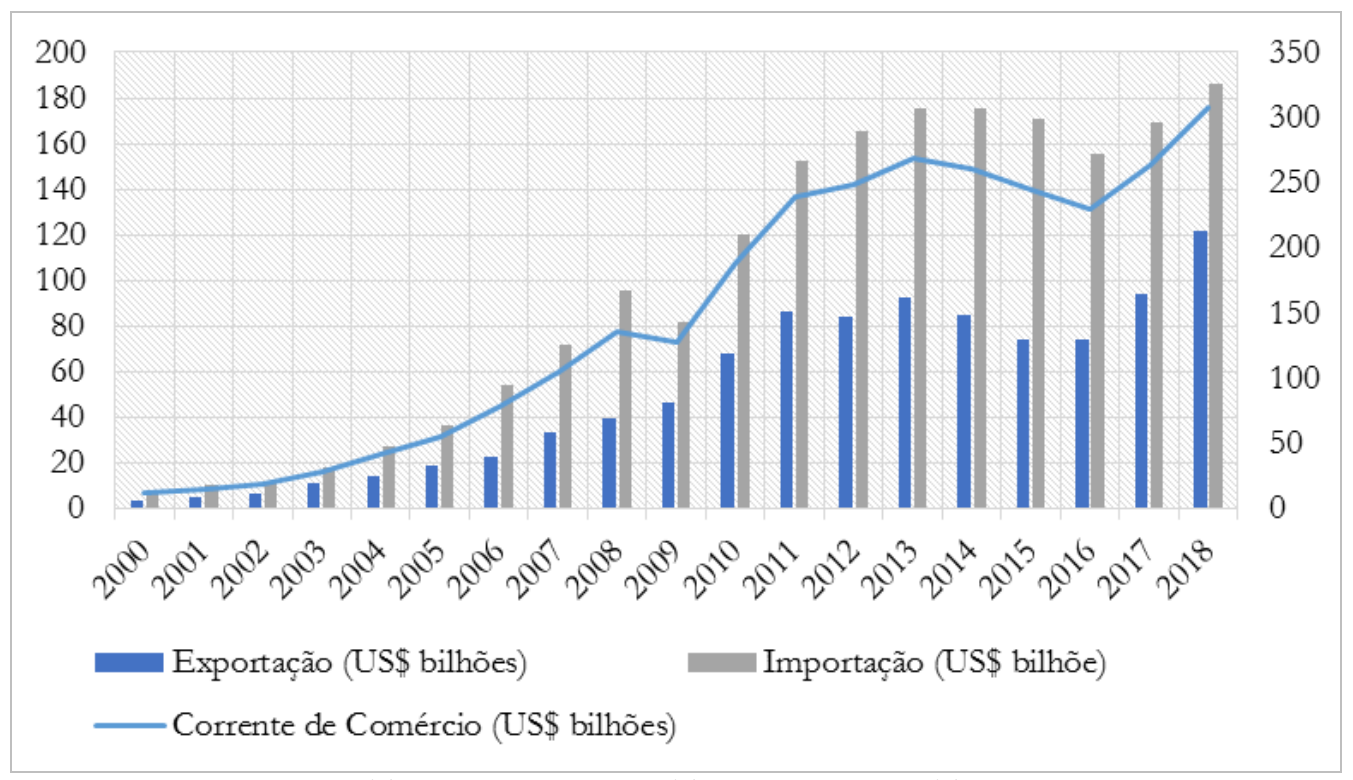

Fonte: World Bank - The World Integrated Trade Solution (WITS). Elaboração própria.

Até o ano de 2002, a China não ocupava lugar de destaque como destino das exportações nem como origem das importações da ALC (composta por 32 países), obtendo uma corrente de comércio (as trocas comerciais, soma das exportações e importações) em torno US $\$ 20$ bilhões. Já em 2018, a corrente de comércio foi de US\$308 bilhões, com as exportações chegando a US\$ 122 bilhões e as importações, a US\$ 186 bilhões (Gráfico 1), com nítida vantagem para o gigante chinês nessas trocas comerciais.

A participação das exportações de produtos primários em 12 países selecionados da América do Sul pode ser vista na tabela 2 para anos 2000, 2004, 20112015 e 2018. Dos países amazônicos, destacam-se: Bolívia, Brasil, Colômbia, Equador, Peru e Venezuela. Os produtos que mais contribuíram para a expansão das exportações foram grãos, minérios e petróleo. Com o forte aquecimento nos preços internacionais desses produtos no começo do século XXI, a expansão das exportações se tornou o principal elemento propulsor do crescimento econômico nesses países. 
| Expansão do capital e ações dos Estados Nacionais na Gran Amazonía (2000-2019): impactos e impasses |

\section{|Thais Virga | Humberto Miranda do Nascimento |}

Tabela 2 - Participação das exportações de produtos primários nas exportações totais - \% do valor total das exportações $\mathrm{FOB}^{1}$

\begin{tabular}{lccccc}
\hline País & $\mathbf{2 0 0 0}$ & $\mathbf{2 0 0 4}$ & $\mathbf{2 0 1 1}$ & $\mathbf{2 0 1 5}$ & $\mathbf{2 0 1 8}$ \\
\hline Argentina & 67.5 & 71.4 & 67.4 & 70.6 & 79.5 \\
Bolívia $^{2}$ & 71.1 & 86.4 & 94.5 & 91.0 & 92.7 \\
Brasil $_{\text {Chile }}$ & 41.6 & 46.6 & 65.9 & 61.9 & 63.9 \\
Colômbia $^{2}$ & 83.8 & 84.9 & 86.2 & 85.2 & 85.7 \\
Equador $_{\text {Guiana }}^{2}$ & 67.5 & 61.6 & 80.6 & 75.8 & 79.3 \\
Paraguai $_{\text {Peru }}$ & 80.1 & 91.3 & 92.1 & 92.3 & 93.9 \\
Uruguai $_{\text {Venezuela }}^{2}$ & 92.5 & 93.3 & 89.2 & 65.9 & 68.1 \\
Suriname $^{2}$ & 77.6 & 80.8 & 92.4 & 89.9 & 88.3 \\
\hline
\end{tabular}

Fonte: CEPAL - CEPALSTAT Base de Datos. Elaboração própria.

Notas 1. Informação revisada pela CEPAL em 01/10/2019; 2. Foram incluídas as reexportações.

Além dos preços, é importante observar, segundo Medeiros e Cintra (2015), que a consolidação da China como um centro manufatureiro mundial produziu efeitos distintos, de "demanda" e "estrutura", sobre os vários países. O "efeito demanda", ou macroeconômico, refere-se ao impacto da expansão chinesa sobre a balança comercial e os investimentos, elucidando o impacto indireto da expansão chinesa ao crescimento das importações dos países exportadores de primários e commodities e à fragilização de seus tecidos industriais. Por outro lado, o "efeito estrutura", ou setorial, diz respeito ao impacto desigual sobre os setores ou atividades desses países, segundo o grau de complementaridade e rivalidade em relação à economia chinesa, aprofundando a heterogeneidade estrutural.

Para dar clareza aos processos que estão alterando a situação regional na Gran Amazonía, fez-se um levantamento com base em várias fontes, que estão sintetizadas no Quadro 1, mostrando as principais frentes de expansão do capital e alguns dos seus efeitos.

Quadro 1 - Principais Frentes de Expansão do Capital e Efeitos nos Países da Gran Amazonía

\begin{tabular}{|l|l|c|}
\hline Países & \multicolumn{1}{|c|}{ Frentes de Expansão no Território / Efeitos } & $\begin{array}{c}\text { Perda de Floresta } \\
\text { Original } \\
\text { (2001 a 2018, em \%) }\end{array}$ \\
\hline Bolívia & $\begin{array}{l}\text { Mineração, Agropecuária (soja e gado) e Petróleo / Enormes } \\
\text { incêndios na zona de Chiquitania (entre o Gran Chaco e a } \\
\text { Amazonía) e Violações de Direitos Indígenas e Trabalhistas } \\
\text { (criminalização no acesso à justiça). }\end{array}$ & $8 \%$ \\
\hline Brasil & $\begin{array}{l}\text { Agropecuária (soja e gado), Mineração, Extrativismo Vegetal } \\
\text { (madeireiras ilegais) / Desmatamento, Incêndios (mobilização } \\
\text { de fazendeiros locais ao que se denominou "Dia do Fogo"), } \\
\text { "grilagem" de terras e crescente Violência a líderes de } \\
\text { movimentos sociais, trabalhadores e indígenas " }\end{array}$ & $18 \%$ \\
\hline Colômbia & $\begin{array}{l}\text { Mineração, Pecuária (gado) / Desmatamento, "grilagem" 2, } \\
\text { Especulação (crescente e ilegal "mercado de terras"). }\end{array}$ & $11,7 \%$ \\
\hline Equador & $\begin{array}{l}\text { Cultivo de Dendê, Cacau, Petróleo e Mineração (cobre, ouro e } \\
\text { prata)/ Desmatamento e Violações de Direitos Trabalhistas. }\end{array}$ & $10 \%$ \\
\hline
\end{tabular}


| Expansão do capital e ações dos Estados Nacionais na Gran Amazonía (2000-2019): impactos e impasses |

| Thais Virga | Humberto Miranda do Nascimento |

\begin{tabular}{|l|l|c|}
\hline Guiana & $\begin{array}{l}\text { Extrativismo Vegetal (madeiras) e Mineração (ouro) / } \\
\text { Ampliação Recente do Desmatamento. }\end{array}$ & $1 \%$ \\
\hline Guiana Francesa & Mineração Ilegal de ouro / Violações de Direitos Indígenas. ${ }^{3}$ & $3 \%$ \\
\hline Peru & $\begin{array}{l}\text { Agricultura (pequena escala), Cultivo de Dendê e Coca, } \\
\text { Extrativismo Vegetal (madeiras) e Mineração (garimpo ilegal } \\
\text { de ouro) / Desmatamento e Violência (a campesinos e } \\
\text { indígenas). }\end{array}$ & $8 \%$ \\
\hline Suriname & $\begin{array}{l}\text { Mineração (garimpo ilegal de ouro, cerca de 60\% vindo de } \\
\text { garimpeiros brasileiros) / Conflitos. }\end{array}$ & $4 \%$ \\
\hline Venezuela & $\begin{array}{l}\text { Mineração (sobretudo de ouro, diamante e coltan, sendo o } \\
\text { país com o maior número de garimpos ilegais da } \\
\text { Amazônia) e Petróleo / Desmatamento e Conflitos entre } \\
\text { multinacionais, colonos e indígenas } 5\end{array}$ & $4 \%$ (estimado) \\
\hline
\end{tabular}

Fonte: Reportagem de Camilla Costa à BBC News Mundo (18/02/2020), Centro de Estudios para el Desarrollo Laboraly Agrario (CEDLA, vários estudos e reports) e pesquisa de campo autoral. Elaboração própria.

Notas: 1. Entre janeiro e setembro de 2019, os ataques e invasões a terras indígenas no Brasil subiram mais de $40 \%$ em relação ao ano anterior, segundo dados do Conselho Indigenista Missionário (CIMI), segundo a BBC News Mundo; 2. Grilagem (posse irregular) realizada por empresários, políticos, narcotraficantes e paramilitares; 3. Conflitos entre garimpeiros e caçadores contra os Wajãpi, guardiões de área cobiçada entre o Amapá e a Guiana Francesa; 4. As atividades de cultivo e transformação (em azeite) do dendê no Peru são controladas por grandes corporações do capital nacional; 5: Conflitos na região do Arco Minero del Orinoco, ao norte do estado de Bolívar, o maior do país.

Quando se associa àqueles setores econômicos em expansão destacados no Quadro 1 a outros segmentos da infraestrutura econômica, o que se nota é uma crescente participação de empresas chinesas em investimentos e projetos bastante controversos, dadas as perdas de floresta original e outros impactos socioterritoriais. A inserção chinesa ampliou os problemas em grande parte dos países amazônicos nos quais investe.

Ao serem observados os impactos mais relevantes em âmbito transnacional, evidenciam-se a degradação e a despossessão como problemas marcantes nas diferentes porções do território amazônico desses países. Sendo assim, considera-se que sem o consentimento dos Estados Nacionais sul-americanos tais impactos não seriam tão intensos, haja vista que estes países autorizaram e/ou aprovaram vários tipos de projetos que produziram um quadro extremamente preocupante de danos sociais e ambientais.

\section{A GRAN AMAZONÍA E SUA RELAÇÃO COM A CHINA: impactos e impasses}

Não é intuito aqui traçar um quadro histórico geral da ocupação dos territórios amazônicos e nem de suas particularidades nos oito países acima citados. Há tempos, a Gran Amazonía é vista pelo capital nacional e internacional como uma fronteira de recursos a ser explorada ${ }^{4}$. As formas mais antigas de relação econômica compreendiam os chamados "ciclos de exploração", que se caracterizavam pela intensidade e pela intermitência.

\footnotetext{
4 Sobre a exploração nas “Amazônias”, consultar trabalhos de Dourojeanni (1990), Amayo Zevallos (1999) e Costa (2012).
} 
| Expansão do capital e ações dos Estados Nacionais na Gran Amazonía (2000-2019): impactos e impasses |

\section{|Thais Virga | Humberto Miranda do Nascimento |}

Recentemente, contudo, a relação econômica passou a ser caracterizada pela extração contínua e em grande escala, visando uma interação econômica mais duradoura entre as fontes de recursos e os interesses externos. Isto só foi possível devido à enorme demanda industrial e urbana da China após 2000, propiciando a criação e a ampliação de "centros de extração" agrícola ou mineral mundo afora e, em espacial, em países com fontes abundantes de produtos primários.

No caso de países latino-americanos, houve um crescimento articulado e abrangente dos segmentos agrícolas, extrativistas e industriais de produção atinentes: ao Agronegócio de grãos (soja, principalmente); à Mineração (ouro, cobre, diamante e outros minérios); ao Petróleo (ambos, com respectivas estruturas de armazenamento ou estocagem); além de Energia (sobretudo, em geração). No gráfico 2, vê-se que, após 2002, houve um forte crescimento nas exportações dos principais produtos básicos da ALC, brevemente interrompido pelos efeitos da crise de 2008 e logo retomado em 2011. Na figura 2, são destacados os investimentos chineses na Gran Amazonía.

Gráfico 2 - ALC: Índices de preços dos principais produtos básicos de exportação selecionados (1990-2019).

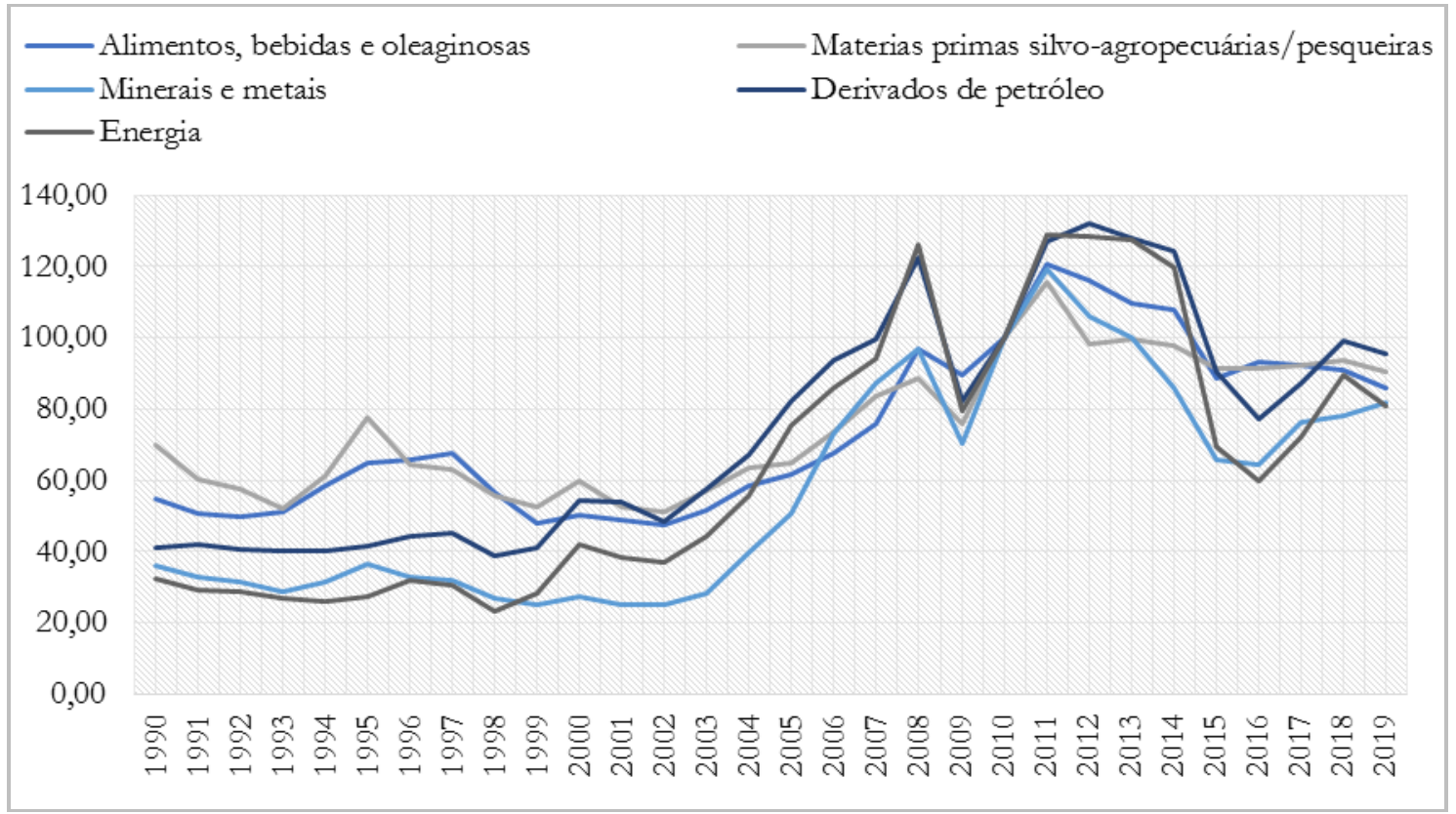

Fonte: CEPAL - CEPALSTAT. Base de Datos. Elaboração própria. 
| Expansão do capital e ações dos Estados Nacionais na Gran Amazonía (2000-2019): impactos e impasses |

|Thais Virga | Humberto Miranda do Nascimento |

Figura 2 - Investimentos Chineses na Gran Amazonía (2018-2019)

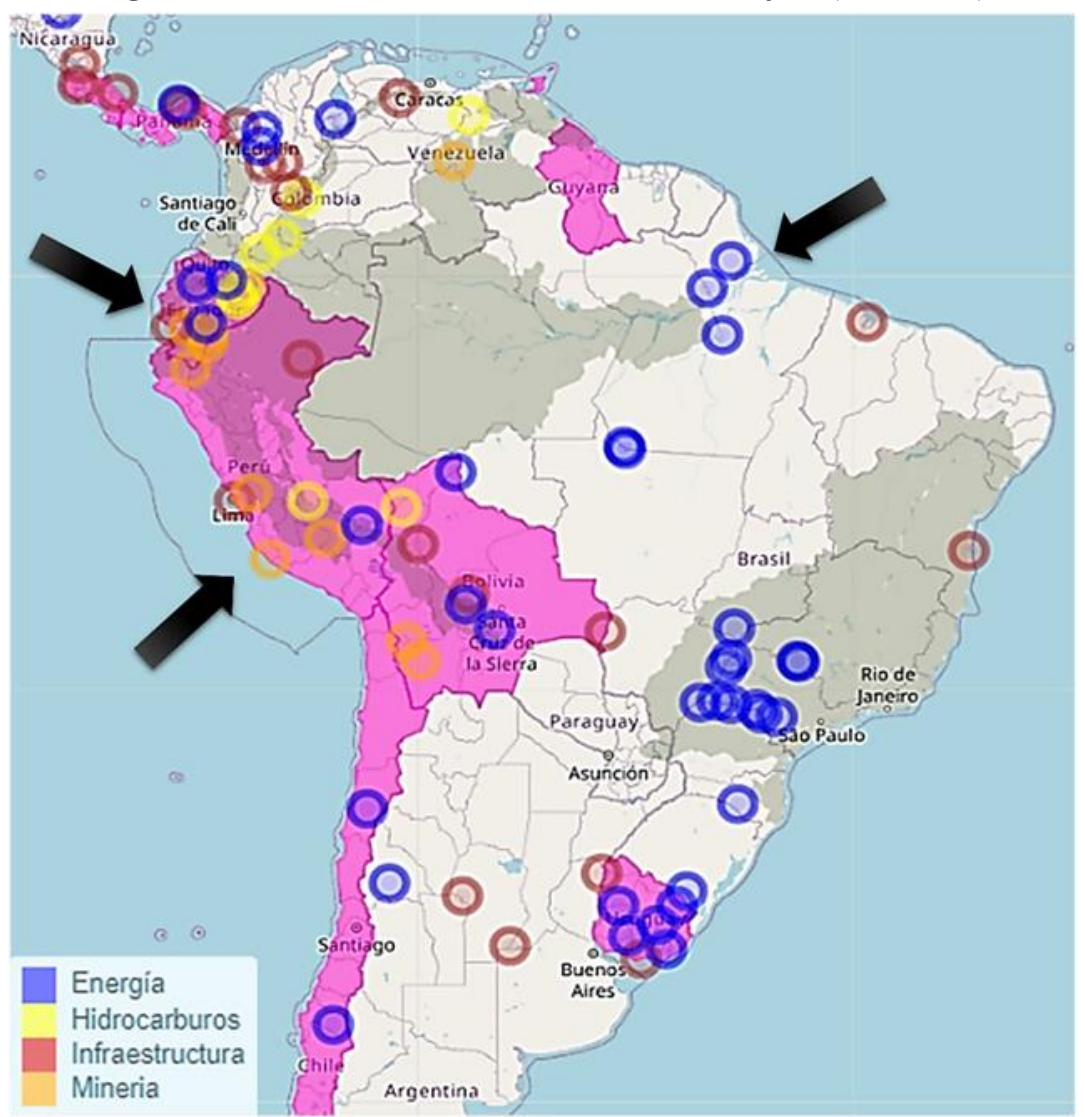

Fonte: Inversiones Chinas en América Latina (2020). As setas, destaques nossos, indicam áreas investimentos na Gran Amazonía. [Figura original disponível em: < https://www.chinaenamericalatina.info/inicio/>]. Nota: As áreas em rosa, de acordo com a citada fonte, dizem respeito às "ecorregiões prioritárias" dos investimentos chineses nas Américas Central e do Sul, como "franja y ruta".

Constatou-se o maior direcionamento dos investimentos chineses, nos últimos anos, para as áreas de mineração e petróleo (hidrocarbonetos) nas porções amazônicas da Bolívia, Peru e Equador, inclusive com a participação da Venezuela na primeira área e da Colômbia, na segunda. Sobre energia e transportes, destaca-se o envolvimento chinês ocorreu em plantas e projetos de hidrelétricas no Brasil, Equador e Peru, e projetos logísticos em direção à Bolívia e Venezuela (Figura 2).

Articulando, então, a degradação ambiental (desmatamentos e queimadas) às violências (a cidadãos e trabalhadores), na sequência, os Quadros 2 e 3 e a Figura 3 apresentam e problematizam tais associações, a partir de casos e exemplos em países amazônicos selecionados, com obras prospectadas, concessionadas, em andamento ou em operação. A partir disto, ficará mais clara a forma de atuação da China na Gran Amaz̧onía, quanto a principais impactos e impasses gerados. 
| Expansão do capital e ações dos Estados Nacionais na Gran Amazonía (2000-2019): impactos e impasses |

|Thais Virga | Humberto Miranda do Nascimento |

Quadro 2 - Impasses e Impactos de Investimentos chineses: Casos no Brasil e Bolívia

\begin{tabular}{|c|c|c|c|c|}
\hline País & Caso(s) / Setor & $\begin{array}{l}\text { Localização / Fase (Prospectado, } \\
\text { Em Andamento ou Operação) }\end{array}$ & $\begin{array}{c}\text { Empresas Envolvidas na Concessão } \\
\text { (construção e operacionalização) }\end{array}$ & Impasses e Impactos Socioambientais Diretos \\
\hline \multirow{2}{*}{ Brasil } & $\begin{array}{l}\text { Usina Hidrelétrica de } \\
\text { São Manoel / Energia }\end{array}$ & $\begin{array}{l}\text { Rio Teles-Pires (formador do Rio } \\
\text { Tapajós) entre os municípios de } \\
\text { Paranaíta (MT) e Jacareacanga (PA). } \\
\text { Em operação desde maio de } 2018 \text {. }\end{array}$ & $\begin{array}{l}\text { Empresa de Energia São Manoel (EESM), } \\
\text { constituída pelos acionistas: EDP BRASIL } \\
\text { S.A., Furnas Centrais Elétricas e China Three } \\
\text { Gorges Corporation (CTG, administradora da } \\
\text { maior usina em capacidade instalada do } \\
\text { mundo, a usina de Três Gargantas). }\end{array}$ & $\begin{array}{l}\text { - EESM enche lago sem aval do IBAMA (Nota 1) e sem } \\
\text { licenciamento ambiental. } \\
\text { - Ausência de processos de consulta. } \\
\text { - Alterações da morfologia fluvial do Rio Teles-Pires, } \\
\text { devido ao barramento. } \\
\text { - Contaminação de peixes e tartarugas que são a base da } \\
\text { alimentação dos povos Kayabi, Apiaká e Munduruku. }\end{array}$ \\
\hline & $\begin{array}{l}\text { Porto São Luís / } \\
\text { Transporte e Logística } \\
\text { (cargas de grãos, } \\
\text { combustíveis e } \\
\text { minérios) }\end{array}$ & $\begin{array}{l}\text { Comunidade Cajueiro - área } \\
\text { preservada por pequenos } \\
\text { agricultores, indígenas e quilombolas } \\
\text { na zona rural de São Luís (MA). } \\
\text { Em andamento desde } 2018 .\end{array}$ & $\begin{array}{l}\text { Empreendimento portuário comandado pela } \\
\text { empresa Terminal de Uso Privado Porto São } \\
\text { Luís (TUP), formada pelo grupo WTorre e } \\
\text { China Communications Construction } \\
\text { Company (CCCC), sócia majoritária do } \\
\text { empreendimento através do braço CCCC } \\
\text { South America Regional Company. }\end{array}$ & $\begin{array}{l}\text { - A TUP alega se dona do terreno onde será construído o } \\
\text { porto em uma área de } 600 \text { há (Nota 2), possuindo títulos } \\
\text { de propriedade irregulares; investigações estão em } \\
\text { andamento sobre suspeita de grilagem e falsificação de } \\
\text { documentos. } \\
\text { - Ausência de consulta a camponeses e ribeirinhos. } \\
\text { - Remoções forçadas de moradores locais. }\end{array}$ \\
\hline Bolívia & $\begin{array}{l}\text { Bloque Nueva Esperanza } \\
\text { / Petróleo }\end{array}$ & $\begin{array}{l}\text { Norte amazônicos do Departamento } \\
\text { de La Paz, na cuenca do Rio Madre de } \\
\text { Dios - entre duas áreas de reserva } \\
\text { (Parque Nacional Madidi e Reserva de } \\
\text { biosfera Pilón Lajas). } \\
\text { Em andamento desde } 2015 .\end{array}$ & $\begin{array}{l}\text { Contrato de exploração sísmica (Nota 3) } \\
\text { celebrado entre as empresas Yancias Petroliferos } \\
\text { Fiscales Bolivianos (YPFB), estatal boliviana, e a } \\
\text { BGP Bolivia, subsidiária da estatal China } \\
\text { National Petroleum Corporation (CNPC). }\end{array}$ & $\begin{array}{l}\text { - A exploração de petróleo do Bloco Nueva Esperanza } \\
\text { pela BGP vem gerando danos em mais de } 1.000 \mathrm{~km} \text { de } \\
\text { selva, abrangendo territórios indígenas Tacana e } \\
\text { Toromona, este um "PIAV" Pueblos Indígenas en Aislamiento } \\
\text { Voluntario. } \\
\text { - Desrespeito constante à Avaliação de Impacto } \\
\text { Ambiental (AIA) e contato forçado de trabalhadores } \\
\text { chineses com a população do PIAV Toromona. } \\
\text { - Prejuízo às formas de subsistência indígena; } \\
\text { contaminação de rios e córregos, mutilação de } \\
\text { castanheiras e palmeiras após as detonações de } \\
\text { explosivos. }\end{array}$ \\
\hline
\end{tabular}

Fonte: Colectivo sobre Financiamiento e Inversiones Chinas, Derechos Humanos y Ambiente (CICDHA) e Felipe (2020). Elaboração própria.

Nota 1: IBAMA - Instituto Brasileiro do Meio Ambiente e dos Recursos Naturais Renováveis.

Nota 2: Área essa onde habitam cerca de 500 famílias da Comunidade Cajueiro, vivendo da pesca artesanal, agricultura familiar, caça e extrativismo.

Nota 3: Exploração que envolve o uso de quase 200 toneladas de explosivos para detonação em um traçado de 21 linhas sísmicas de 48 km cada uma.

\begin{tabular}{llll|l|} 
Rev. InterEspaço & Grajaú/MA & v. 07 & p. $01-26$ & 2021
\end{tabular}


| Expansão do capital e ações dos Estados Nacionais na Gran Amazonía (2000-2019): impactos e impasses |

|Thais Virga | Humberto Miranda do Nascimento |

Quadro 3 - Impasses e Impactos dos Investimentos chineses: Casos no Equador e Peru

\begin{tabular}{|c|c|c|c|c|}
\hline País & Caso(s) / Setor & $\begin{array}{l}\text { Localização / Fase (Prospectado, } \\
\text { Em Andamento ou Operação) }\end{array}$ & $\begin{array}{l}\text { Empresas Envolvidas na Concessão } \\
\text { (construção e operacionalização) }\end{array}$ & Impasses e Impactos Socioambientais Diretos \\
\hline \multirow[t]{2}{*}{ Equador } & $\begin{array}{l}\text { Proyecto Mirador / } \\
\text { Mineração de grande } \\
\text { escala a céu aberto } \\
\text { (cobre) }\end{array}$ & $\begin{array}{l}\text { Província de Zamora Chinchipe } \\
\text { (vale do Rio Quimi na Cordillera } \\
\text { del Cóndor). } \\
\text { Em Andamento desde 2012, } \\
\text { atualmente em "explotación". }\end{array}$ & $\begin{array}{l}\text { Concessão à empresa Ecuacorriente S.A. } \\
\text { (ECSA), subsidiária do consórcio China } \\
\text { Railway Construction Corporation Limited } \\
\text { (CRCC) e Tongling Nonferrrous } \\
\begin{array}{l}\text { Investment Co. Ltd. (TNM), ambas estatais } \\
\text { chinesas. }\end{array}\end{array}$ & $\begin{array}{l}\text { - Processo de concessão e outorga de licenças ambientais } \\
\text { realizados sem qualquer consulta prévia. } \\
\text { - Efeitos imediatos na Comunidad Amazónica de Acción Social } \\
\text { Cordillera del Cóndor Mirador (CASCOMI): manipulação do } \\
\text { preço da terra; despejo de famílias; denúncias de abusos, } \\
\text { demissões ilegais e acidentes. } \\
\text { - Contaminação em mais de } 200 \text { incubadoras ou fontes de } \\
\text { água localizadas na área de influência do projeto. }\end{array}$ \\
\hline & $\begin{array}{l}\text { Coca Codo Sinclair / } \\
\text { Hidrelétrica }\end{array}$ & $\begin{array}{l}\text { Província de Napo no Rio Coca. } \\
\text { Em Operação (barragem com } \\
\text { construção finalizada em 2016). }\end{array}$ & $\begin{array}{l}\text { Concessão à Sinohydro Corporation, estatal } \\
\text { chinesa de engenharia e construção de } \\
\text { hidrelétricas muito internacionalizada. }\end{array}$ & $\begin{array}{l}\text { - A barragem foi construída numa zona de transição } \\
\text { montanhosa entre os Andes e a Amazônia, de grande } \\
\text { biodiversidade e instabilidade sísmica (o vulcão El } \\
\text { Reventador está ativo). } \\
\text { - Ao desviar os fluxos de águas de cachoeiras e afluentes } \\
\text { próximos, a barragem já afeta a ictiofauna, com forte } \\
\text { redução de peixes aos habitantes da zona do Rio Tigre. }\end{array}$ \\
\hline \multirow[b]{2}{*}{ Peru } & $\begin{array}{l}\text { Mina Subterránea Río } \\
\text { Blanco / Mineração } \\
\text { (cobre) }\end{array}$ & $\begin{array}{l}\text { Norte Amazônico do } \\
\text { Departamento de Piura, no Rio } \\
\text { Blanco. } \\
\text { Prospectado, com reserva já em } \\
\text { fase exploração. }\end{array}$ & $\begin{array}{l}\text { Projeto operado pela empresa Zijin } \\
\text { Mining, estatal chinesa produtora e } \\
\text { refinadora de ouro, cobre e metais não } \\
\text { ferrosos, já autuada nesse país por colapso } \\
\text { de barragem e grande derramamento de } \\
\text { ácido. }\end{array}$ & $\begin{array}{l}\text { - O projeto ameaça o ecossistema dos pântanos andinos } \\
\text { que irriga as bacias da região de Piura e abriga espécies } \\
\text { endêmicas vulneráveis. } \\
\text { - Violência social com morte e tortura de "ronderos", } \\
\text { líderes camponeses que se opõem ao projeto. }\end{array}$ \\
\hline & $\begin{array}{l}\text { Hidrovía Amazónica / } \\
\text { Transportes e Energia } \\
\text { (Nota 1) }\end{array}$ & $\begin{array}{l}\text { Rios Huallaga, Ucayali e Marañón } \\
\text { nos Departamentos de Loreto e } \\
\text { Ucayali. } \\
\text { Prospectado }\end{array}$ & $\begin{array}{l}\text { Projeto concessionado à COHIDRO, } \\
\text { formada pelas empresas Construcción y } \\
\text { Administración S.A. (CASA), peruana, e à } \\
\text { chinesa Sinohydro. }\end{array}$ & $\begin{array}{l}\text { - O projeto ameaça os cursos fluviais mais relevantes de } \\
\text { toda a Bacia do Amazonas e, consequentemente, a } \\
\text { ictiofauna e as populações que dependem dos rios. } \\
\text { - A localização do projeto possui relevância geoestratégica, } \\
\text { tendo em vista que: após nascer nos Andes peruanos, o } \\
\text { Amazonas ganha densidade fluvial exatamente na área de } \\
\text { confluência entre os rios Marañón e Ucayali. }\end{array}$ \\
\hline
\end{tabular}

Fonte: CICDHA, Palma (2017), Bojórquez (2014) e pesquisa de campo própria (VIRGA, 2019). Elaboração própria.

Nota 1: O projeto da Hidrovía Amaźnica propõe, inicialmente, estabelecer um canal dragado e ininterrupto de navegação fluvial ao longo de quase $2.700 \mathrm{~km}$ de rios na Amazônia Peruana e Tri-Fronteiriça entre o Peru, o Brasil e a Colômbia. Mas, atenta-se à construção de grandes hidrelétricas no core de negócios da concessionária chinesa Sinohydro. 
| Expansão do capital e ações dos Estados Nacionais na Gran Amazonía (2000-2019): impactos e impasses |

|Thais Virga | Humberto Miranda do Nascimento |

Figura 3 - Síntese das Pressões na Gran Amazonía decorrentes das atividades de petróleo e minérios, obras de infraestrutura viária e atividade agropecuária.

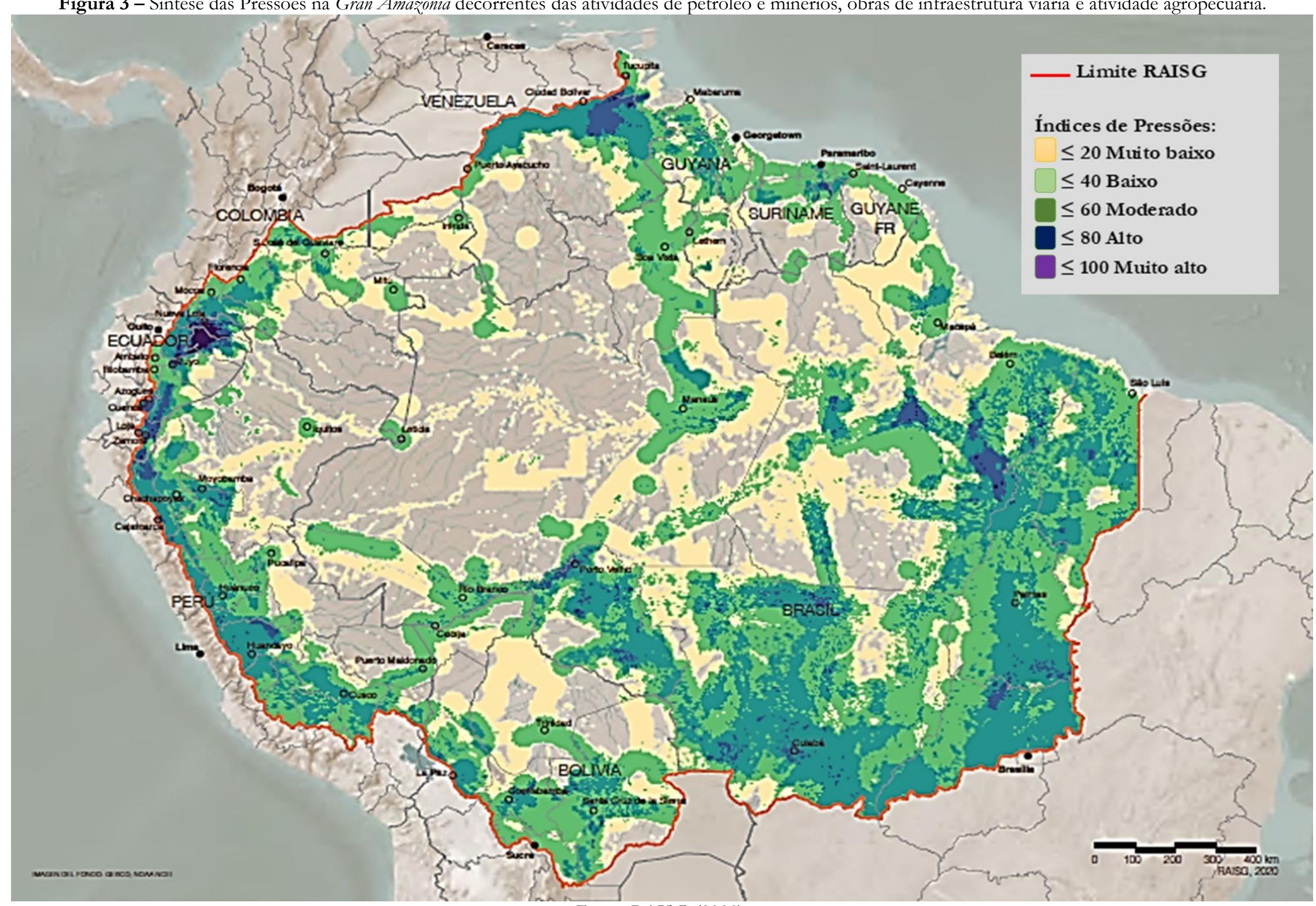

Fonte: RAISG (2020). 
| Expansão do capital e ações dos Estados Nacionais na Gran Amazonía (2000-2019): impactos e impasses |

\section{|Thais Virga | Humberto Miranda do Nascimento |}

Explorando o conjunto de informações nos Quadros 2 e 3, destaca-se que, dentre os países andino-amazônicos, a Bolívia ampliou fortemente os laços econômicos de dependência externa com a República Popular da China a partir de 2015. Tal dependência caracteriza-se pelo país asiático ser: o principal parceiro comercial $\left(5^{\circ}\right.$ maior importador de minérios da Bolívia), o maior credor (cerca de 15\% da dívida externa total boliviana), além de ter consolidado a presença de mais de 100 empresas operando legalmente em território boliviano desde 2016, segundo estudos e dados disponibilizados pelo CICDHA.

Já a Figura 3 mostra que as pressões não apenas se ampliaram, mas são generalizadas e, ao mesmo tempo, seletivas (no sentido de, localmente, priorizarem rotas de escoamento vinculados aos fluxos de exportação) em todos os territórios amazônicos dos respectivos países situados na Gran Amazonía, que conta com 65,8\% de suas áreas, analisadas pela Fundación Gaia Amazonas (Colômbia) para a RAISG, comprometidas com algum tipo de pressão "instalada o em curso". Segundo o estudo da Fundação, publicado pelo Instituto Socioambiental (ISA) no Brasil:

\footnotetext{
El análisis arroja que el 7\% del territorio amazónico se encuentra bajo presión "muy alta" y el 26\%, "alta". Las áreas con mayor presión se localizan en las zonas periféricas del bioma, en las ronas montañosas y de piedemonte situadas al occidente, especialmente en Ecuador, al norte de Venequela y, hacia el sur, en Brasil... [ver Figura 3] (...) Se observa que Ecuador es el caso más dramático, con $88 \%$ de su territorio amazónico impactado por algún tipo de presión, clasificando más de la mitad (63\%) dentro de los indicadores de presión "alta" (18\%) $y$ "muy alta" (45\%) (RAISG, 2020, p. 41).
}

O Equador, particularmente, começou a estabelecer maiores laços com a China, a partir da chegada de Rafael Correa ao poder em 2007. Segundo Neher e Pontes (2013, n.p.), a China buscava de fontes de recursos naturais para sua gigantesca indústria: "o país sul-americano vendia $75 \%$ do seu petróleo para os Estados Unidos. Hoje, estima-se que envie mais da metade para os chineses, e a tendência é que a cifra cresça”. A China avança também em outros segmentos no país, sobretudo, em projetos de mineração e em hidrelétricas. Assim, no Equador, avolumaram-se obras com efeitos socioambientais danosos e ligados a violações de direitos humanos envolvendo empresas chinesas, conforme denúncias de coletivos e ONGs (CICDHA).

Quanto ao Peru, ressalta-se que após a assinatura do Tratado de Livre Comércio (TLC) com a China em 2009, na gestão de Alan García, tornou-se o país sul-americano que mais tem atraído contestáveis e robustos aportes asiáticos nos setores de mineração. A partir da gestão de Ollanta Humala, em 2011, o setor de infraestrutura (segmentos de transporte e energia) também foi favorecido em âmbito regional. 
| Expansão do capital e ações dos Estados Nacionais na Gran Amazonía (2000-2019): impactos e impasses |

| Thais Virga | Humberto Miranda do Nascimento |

Particularmente, na Amazônia Peruana, de acordo com o CICDHA, esse processo de dependência com a China correspondeu: a um alto nível de reservas minerais e um marco jurídico claramente voltado à promoção de investimentos privados, através de normas fiscais, trabalhistas e ambientais flexibilizadas (em especial, à grandes corporações chinesas); a uma judicialização de defensores ambientais, com criminalização de protestos; além de violações em termos de obrigações extraterritoriais. Nesse sentido, infere-se que o Peru se torne o país amazônico com o maior número de projetos envolvendo capital chinês e múltiplos e graves impactos negativos.

Esta situação ganhou maior relevância na medida em que os Estados Nacionais passaram a atuar efetivamente para a expansão do capital em toda a Gran Amazonía.

\section{INICIATIVAS NACIONAIS PARA A EXPANSÃO DO CAPITAL NA GRAN AMAZONÍA}

A inserção chinesa na Gran Amaz̧onía destaca-se não apenas pelas oportunidades geradas $^{5}$ pelo crescimento das exportações e incremento das importações, mas, sobretudo, pelo aumento do número de países que apresentam impactos ambientais negativos e violações de direitos sociais básicos. Decorrente dessa inserção, o andamento de controversos projetos numa região tão estratégica e sensível não responde, tão somente, aos interesses de multinacionais e empresários locais e regionais, mas também a um de tipo de articulação com os Estados Nacionais.

Durante o período analisado, 2000-2019, várias das iniciativas nacionais levaram adiante incentivos econômicos vinculados à demanda externa, abrindo-se às frentes de expansão do capital chinesas. Nesse ínterim, o consentimento dos Estados Nacionais para atrair o capital chinês constituiu o expediente usado para materializar acordos de longo prazo, em relação aos quais os países da região deram respostas ativas, aproveitando o "boom de preços" das commodities.

Com o aumento dos investimentos chineses na região amazônica, os países encontraram tanto nos governos de linha "democrático-popular" como de linha "liberalconservadora" ações efetivas nesse sentido, com algumas diferenças importantes. Nos governos de linha "democrático-popular" buscava-se viabilizar o desenvolvimento nacional com base nas divisas geradas no mercado de commodities, ainda que, em muito,

\footnotetext{
${ }^{5}$ A CEPAL reconheceu e estimulou os países da região a aproveitarem o "boom de commodities" como uma oportunidade para ampliar a cooperação com a China em prol do desenvolvimento latino-americano. Ver: CEPAL, 2015.
} 
| Expansão do capital e ações dos Estados Nacionais na Gran Amazonía (2000-2019): impactos e impasses |

\section{|Thais Virga | Humberto Miranda do Nascimento |}

flexibilizando legislações ambientais e gerando impactos socioterritoriais. Nos governos de linha "liberal-conservadora", foram abertas aos capitais externos mais vantagens na exploração de recursos nacionais, o que resultou em formas ainda mais permissivas e predatórias do ponto de vista social e ambiental, violando direitos humanos e descumprindo práticas já estabelecidas de conservação do ecossistema amazônico. O fato é que, em relação às duas linhas, os conflitos socioambientais se generalizaram.

Este cenário foi favorecido pela crescente intervenção econômica e política de empresas estrangeiras na Gran Amaz̧onía, com direta associação a transformações espaciais resultantes de incentivos, disposições legais e fiscais concedidos pelos Estados nacionais. A seguir, são destacadas políticas, leis e/ou direcionamentos, por países, dando um amplo panorama das medidas governamentais envolvendo a porção amazônica dos territórios nacionais, a fim de mostrar que houve uma convergência de propósito entre as estratégias nacionais e as frentes de expansão do capital na região.

A Bolívia, após nacionalizar minas de estanho e zinco pertencentes ao expresidente e empresário Sánchez de Lozada em 2007, durante a gestão presidencial de Evo Morales e Alvaro García Linera, o governo boliviano promulgou algumas leis e decretos que ampliaram o desmatamento e incêndios na Amazônia, além do fortalecimento de conflitos socioespaciais. Destacam-se a seguir as consequências desses atos legais:

- Lei No 337 (11/01/2013): Ley de Apoyo a la Producción de Alimentos y Restitución de Bosques on Ley de Desmontes (cf. CEDIB, 2015), resultou num aumento do desmatamento em mais de 200\% apenas entre 2013 e 2015.

- Lei No 741 (29/09/2015): Ley de Autorización de Desmonte hasta 20 hectáreas para Pequeñas Propiedades y Propiedades Comunitarias o Colectivas para Actividades Agrícolas y Pecuarias. Resultou num forte aumento de "queimadas legais", sobretudo por cocaleros (camponeses associados e autorizados pelos governos), incentivando o mercado ilegal de coca em todo o país e a comercialização de folhas de coca a mercados não autorizados.

- Decreto Supremo No 3973 (09/07/2019):

En los departamentos de Santa Cruz y Beni, se autoriza el desmonte para
actividades agropecuarias en tierras privadas y comunitarias, que se enmarque en
el Manejo Integral y Sustentable de Bosques y Tierra, conforme a los
instrumentos de gestión específicos aprobados por la Autoridad de Fiscalización
y Control Social de Bosques y Tierra - ABT, y sus Planes de Uso de Suelo
vigentes.

Assim, em ambos os departamentos, foram permitidas queimadas controladas, de acordo com as normas que passaram a viger. Como resultado, os incêndios se ampliaram na região de Chiquitania, foco do maior incêndio florestal da história boliviana. 
| Expansão do capital e ações dos Estados Nacionais na Gran Amazonía (2000-2019): impactos e impasses |

\section{|Thais Virga | Humberto Miranda do Nascimento |}

Em suma, apesar de, no seu começo, o governo Morales ter nacionalizado setores econômicos estratégicos ao desenvolvimento nacional (como o gás natural), visando melhor controlá-los e garantir a segurança alimentar da população, tempos depois, acabou submetendo o país às frentes de expansão do capital, sobretudo aos grandes empresários ligados às exportações da agroindústria e da pecuária (JEMIO, 2019). Nesse sentido, convém lembrar do aval concedido pelo Estado a empresas chinesas para contactar povos indígenas isolados do PIAV Toromona em 2017, com vistas a viabilizar o projeto petroleiro Bloque Nueva Esperanza.

No Brasil, durante os governos de Lula e Dilma Rousseff, entre 2004 e 2014, o Brasil foi elogiado por suas ações na Amazônia, devido à forte redução do desmatamento na região (próxima a 80\% no período). O discurso desses governos era, todavia, contraditório, pois autorizava a exploração de recursos naturais para promover o "bemestar social" ao mesmo tempo em que estimulava as relações comerciais com a China (MORENO, 2015).

Assim, o cenário de degradação da Amazônia brasileira piora consideravelmente a partir do segundo mandato de Rousseff, durante a gestão de Michel Temer e, sobretudo, na gestão do atual presidente, Jair Bolsonaro. A seguir, ressaltam-se os direcionamentos principais:

- Decreto (29/10/2017) de regularização fundiária de áreas rurais da União na Amazônia Legal, regulamentando a Lei No 11.952 (de 25/06/2009) e instituindo o Programa Terra Legal. Apesar de o decreto ter limitado a venda de terras da Amazônia a estrangeiros, o pouco período de carência para revender a terra (de três anos após a titulação) acabou favorecendo a apropriação delas por empresários locais e regionais ligados às atividades de exploração dos recursos naturais amazônicos.

- Projeto de Lei No 5.807 (19/06/2013): Novo Marco Regulatório da Mineração, aprovado no auge da demanda chinesa por minérios. O referido PL foi criticado por ampliar a receita advinda da Compensação Financeira pela Exploração de Recursos Minerais (CFEM), pois o PL,

\footnotetext{
[...] apenas visou um texto fiscalista sem procurar viabilizar os aspectos de investimentos em projetos com inovação tecnológica avançada nem tampouco estimular a pesquisa mineral ou criar mecanismos para recuperação de áreas impactadas após a exploração (FRIAS et al., 2016).
}

Isto beneficiaria as gigantes Vale S.A. e a britânica Anglo American PLC, ambas interessadas nas reservas minerais da floresta amazônica brasileira, bem como os grupos de investimento chineses interessados nas enormes reservas na Bacia do Tapajós (MORENO, 2015). 
| Expansão do capital e ações dos Estados Nacionais na Gran Amazonía (2000-2019): impactos e impasses |

| Thais Virga | Humberto Miranda do Nascimento |

- Decreto No 9.142 (28/08/2017): extinção da Reserva Nacional de Cobre e seus Associados (RENCA). Assinado pelo presidente Michel Temer, o decreto extinguiu a área de reserva entre os estados do Amapá e o Pará, liberando a região para a exploração privada de minérios. A pressão foi tanta que, em setembro do mesmo ano, o presidente revogou o decreto.

- Medida Provisória No 910 (10/12/2019), conhecida como a "MP da Grilagem", visando a Regularização Fundiária sobre terras "de domínio da União ou do Instituto Nacional de Colonização e Reforma Agrária - Incra, por meio da alienação e da concessão de direito real de uso de imóveis". A MP permite que terras públicas desmatadas com até 2,5 mil hectares se tornem propriedade de quem as ocupou irregularmente, o que levou à explosão de casos de apropriação forçada de terras por parte de fazendeiros e grileiros, aumentando a violência contra as populações locais na Amazônia.

- Em 19/02/2020, o conselho do Programa de Parcerias e Investimentos (PPI) do governo federal incluiu 22 novos projetos na lista de empreendimentos a serem concedidos à iniciativa privada, autorizando a concessão de florestas para exploração madeireira em áreas das unidades de conservação ambiental Humaitá, Iquiri e Castanho no estado do Amazonas.

- O polêmico projeto portuário privado localizado em São Luís, capital do estado do Maranhão, localizado na zona camponesa e quilombola do Cajueiro, vem causando polêmica. Vide reportagem de Felipe (2020) ao jornal The Intercept Brasil intitulado "Como a grana da China desaloja pobres no Maranhão - com o aval de Flávio Dino”. Sendo Dino o atual governador do Maranhão.

Enfim, apesar de discursos mais progressistas sobre as oportunidades relacionadas ao ciclo de commodities, os sucessivos governos brasileiros, de espectros democráticopopular a liberal-conservador, elevaram de diferentes maneiras o nível de impactos negativos ao meio ambiente e às populações tradicionais na Amazônia brasileira.

Já na Colômbia, por muito tempo, o Estado tratou a Amazônia como um território de violência armada e das guerrilhas. Começou a mudar a forma de atuação durante o andamento do Acordo de Paz com as Forças Armadas Revolucionárias da Colômbia FARC, sob a presidência de Santos. Até então, para sua própria proteção e isolamento, as FARC tinham interesse em manter a "floresta em pé". Porém, com o Acordo e a desmobilização das FARC, a grilagem e o desmatamento voltou a avançar naquela porção amazônica. Para conter os danos, o presidente Iván Duque criou, em 27/09/2018, o Consejo Nacional de Lucha contra la deforestación, objetivando "identificar núcleos de deforestación y sus causas y para recomendar las acciones necessárias", sem maiores especificações.

A Colômbia passou a firmar acordos de negócios com a China, mas a maioria dos projetos possuem conflitos socioterritoriais e não está localizada na Amazônia. Somente o 
| Expansão do capital e ações dos Estados Nacionais na Gran Amazonía (2000-2019): impactos e impasses |

\section{|Thais Virga | Humberto Miranda do Nascimento |}

interesse na exploração de petróleo na região persiste, mesmo havendo resistência popular. Este é o caso do projeto Bloque Petrolero El Nogal, ao sul do Departamento Amazônico de Caquetá. Concessionado em 2006 pelo governo de Uribe à empresa britânica Emerald Energy PLC Colombia Company, que foi adquirida em 2009 pela estatal chinesa Sinochem, petroleira de Pequim, o projeto enfrenta há mais de uma década resistência por parte de campesinos locais que se juntaram no que ficou conhecido como "Plantón Puente La Resistencia".

Quanto aos possíveis impactos futuros, salienta-se que o bloco possui uma área de mais de 239 mil hectares em seis municípios do departamento de Caquetá - Florencia, Morelia, Belén de los Andaquíes, Albânia, San José del Fragua e Valparaíso —, podendo acarretar em bundimientos (ou afundamentos) da zona e contaminação de águas subterrâneas e no Rio Pescados (base da alimentação e ocupação da população).

No Equador, após a conclusão de alguns milhares de quilômetros da rodovia Troncal Amaźnica (E45), ${ }^{6}$ realizada pelo presidente conservador Gustavo Noboa, o "excoronel esquerdista" Lúcio Edwin Gutiérrez Borbúa muda de opinião ao assumir o poder, viajando aos Estados Unidos e assinando um acordo de livre-comércio com o governo de George W. Bush. Esse mandatário planejava aprovar a Ley Trole III, que propunha reformas nos setores de petróleo e eletricidade, para facilitar a participação do capital privado, chamando a atenção de multinacionais conhecidas como Big Oil ou Supermajors, por causa das amplas reservas de hidrocarbonetos da Amazônia equatoriana. Como medidas, destacam-se:

- Em 2006, no segundo ano do mandato presidencial de Palacio, o governo declarou caducidade do contrato assinado com a empresa Occidental Petroleum para exploração petroleira na área de reserva entre as províncias amazônicas de Sucumbios e Orellana, devido a graves violações ao contrato, às leis e aos direitos da população durante as operações no bloque 15. Ademais, o presidente Alfredo Palacio promoveu a reforma da "ley de hidrocarburos", visando aumentar a porcentagem do Estado na distribuição de lucros nos blocos de petróleo do país, já que as transnacionais ficavam com cerca de $80 \%$ e o Estado $20 \%$ (VOGLIANO, 2009).

- Descoberto em 2006, o Yacimiento Fruta del Norte foi anunciado por Palacio como um dos maiores depósitos de ouro no mundo, localizado na província de ZamoraChinchipe. Mas, em 2008, na gestão de Correa, que o referido projeto de exploração mineral foi efetivamente impulsionado, sendo duramente criticado por ser instalado próximo à reserva de La Zarza. O projeto foi concessionado à gigante canadense Kinross Gold, em meio a inúmeras denúncias por parte dos indígenas e

\footnotetext{
${ }^{6}$ Rodovia que une cinco províncias amazônicas do Equador: Sucumbíos, Napo, Pastaza, Morona Santiago e Zamora Chinchipe.
} 
| Expansão do capital e ações dos Estados Nacionais na Gran Amazonía (2000-2019): impactos e impasses |

\section{|Thais Virga | Humberto Miranda do Nascimento |}

camponeses locais de contaminação das águas fluviais do entorno. As pressões foram tantas que o projeto ficou parado por anos, até ser retomado no final do mandato de Correa e inaugurado na gestão de Lenín Moreno em 2019, com a empresa Kinross tendo vendido sua parte à outra mineradora canadense, a Lundin Gold.

- Após o Equador ter anunciado a preservação do Parque Nacional Yasuní, entre os Rios Napo e Curaray, nas províncias de Napo e Pastaza, caso recebesse aportes da ordem de US\$ 3,6 bilhões de ajuda internacional, na iniciativa então chamada de Yasuni ITT, Correa consegue apenas US\$ 13 milhões e anuncia a exploração petrolífera na região anos depois. Em junho de 2013, anuncia que a estatal China National Petroleum Company investiria US $\$ 12,5$ bilhões na modernização e construção de novas refinarias no país.

- Por fim, em 13/03/2018, durante governo de Moreno, foi aprovada a Ley Orgánica Especial de la Circunscripción Territorial Especial Amazónica, prevendo o planejamento territorial integrado da Amazônia Equatoriana, através da criação de um Conselho de Planejamento Interinstitucional. Recebe, inicialmente, um aporte superior a US\$ 300 milhões. Todavia, em maio de 2019, o presidente anunciou que "se dispone a vender millones de hectáreas de selva tropical a la petrolera Big Oil, comprometiendo las tierras que desde hace siglos habitan los Waorani" (ÀRIAS, 2019).

Com relação à Guiana, apesar de o governo de David Granger ter se comprometido na ONU Meio Ambiente com o documento "Estrategia de Desarrollo del Estado Verde: Visión 2040", o qual prevê-se investimentos no ecoturismo, um teto para emissões de $\mathrm{CO}^{2}$ e o aumento da conservação da floresta amazônica do país, as descobertas recentes de enormes reservas de petróleo e minérios nessa região poderão tirar o país desse compromisso de defesa da Amazônia (YOUKEE, 2019).

Com as descobertas offshore realizadas no território guianês desde 2015 e com a descoberta de petróleo no bloco Stabroek no final de 2019, acrescentou-se mais de 6 bilhões de barris às reservas existentes, chamando a atenção de grandes petrolíferas estrangeiras. Anunciado pela petrolifera Exxon Mobil, 45\% do bloco Stabroek é operado por ela tendo como sócias a estadunidense Hess Corp (30\%) e a chinesa CNOOC (25\%).

No Peru, em meio a intensos conflitos entre indígenas e o governo peruano, o presidente Alan García fora um exitoso estimulador do desenvolvimento de atividades extrativistas e exploratórias na Amazônia peruana. Em um controverso artigo ao jornal El Comercio, em 2007, García explicou o que chamou de "síndrome del perro del hortellano" para justificar a necessidade de explorar a região, dizendo que:

Así pues, hay muchos recursos sin uso que no son transables, que no reciben inversión y que no generan trabajo. Y todo ello por el tabú de ideologías 
| Expansão do capital e ações dos Estados Nacionais na Gran Amazonía (2000-2019): impactos e impasses |

\section{|Thais Virga | Humberto Miranda do Nascimento |}

superadas, por ociosidad, por indolencia o por la ley del perro del hortelano que reza: "Si no lo hago yo que no lo haga nadie" (GARCÍA, 2007, p. 1).

Desta maneira, a exploração econômica da Amazônia ganharia reforço e efeitos danosos. Todavia, o Estado parece ter amenizado tal quadro nos anos seguintes:

- Em 2010, segundo Elbein (2019), García e o então presidente brasileiro Lula firmaram acordo para a construção de 22 grandes barragens na bacia amazônica nos Andes, sobretudo nos rios Marañón e Ucayali, principais canais do Rio Amazonas. Segundo o autor,

A energia gerada por essas barragens iria expandir enormemente a mina de ouro e de cobre das Minas Conga no Peru, tornando-a uma das maiores do mundo. A expansão das Minas Conga teria despejado diariamente 85.000 toneladas de rejeitos tóxicos e de metal na bacia do rio Ucayali (ELBEIN, 2019).

- Dentre as minas, a principal de ouro, Yanacocha, localizada no Departamento de Cajamarca - região mais pobre do norte do Peru, fora muito estimulada pelo presidente Ollanta Humala, apesar das inúmeras manifestações populares fortemente reprimidas. A mina começou a produzir em 2014.

- Humala também autorizou vários outros projetos nos setores de infraestrutura (transportes e energia), dentre esses a rodovia IIRSA Norte (ligando a costa norte peruana às regiões montanhosas e amazônicas) e o projeto da Hidrovía Amazónica (depois concessionada à chinesa Sinohydro durante a gestão de PPK).

- O país então avançou na criação de reserva protegidas. Em 10/01/2018, na gestão presidencial de PPK, foi oficializada a criação do Parque Nacional Yaguas em área de 860 mil hectares no Departamento de Loreto. Em maio de 2019, durante a presidência de Martín Vizcarra, é lançada uma iniciativa de planejamento único no país, do tipo público-privada, em parceria com a população local e povos indígenas, intitulada Patrimonio Natural del Perú, com foco na proteção do meio ambiente e das pessoas da Reserva Nacional Pacaya Samiria, em Loreto.

A economia do Suriname, por sua vez, baseia-se na produção de ouro, seguida pela de bauxita e da exportação de alumínio. Neste país, houve denúncias relacionadas à crescente exploração ilegal de minérios nos últimos anos e às constantes violações de direitos humanos por parte do Estado, especificamente sobre a região amazônica, chegando-se a acusar o presidente Dési Bouterse de ditador.

Em 2011, Bouterse, ao receber a presidente brasileira Dilma Rousseff, tratou de um projeto rodoviário transamazônico que ligaria a capital Paramaribo ao estado do Amapá, no Brasil, visando promover as economias dos respectivos países, inclusive, com a possibilidade de explorarem conjuntamente recursos na zona central e sul do Suriname, caracterizada por florestas tropicais originais.

Por fim, sobre a Venezuela, ao sul do Rio Orinoco, na fronteira com o Brasil, numa área amazônica de cerca de 112 mil km² (cerca de 12\% do território venezuelano) 
| Expansão do capital e ações dos Estados Nacionais na Gran Amazonía (2000-2019): impactos e impasses |

\title{
|Thais Virga | Humberto Miranda do Nascimento |
}

constam as maiores riquezas minerais encontradas recentemente, em especial, ouro e diamante, perpassando exatamente a área dos indígenas Yanomami, caracterizada como o "maior território indígena coberto por floresta em todo o mundo" (ELY, 2017). Com a forte queda do preço e da produção do petróleo nos últimos anos, o Estado, durante a gestão de Nicolás Maduro, voltou-se às áreas ricas em minérios:

- Em 2016, retomando uma ideia antiga de Chávez, Maduro decreta a criação da Zona de Desarrollo Estratégico Nacional Arco Minero del Orinoco (AMO). Apesar da região caracterizar-se como zona tradicionalmente mineira, explorada, inclusive, por indígenas venezuelanos e brasileiros, o plano de Maduro concedia esta zona a empresas estrangeiras de mineração, desde que se associassem, na forma de empresas mistas, com as estatais venezuelanas.

- O avanço desta atividade econômica na Amazônia Venezuelana soma-se a outras ameaças socioambientais, como ressalta Ely (2017):

\begin{abstract}
O que ameaça sua soberania nos dias atuais é a ação de garimpeiros, que trabalham ilegalmente transmitindo doenças mortais como malária e poluindo os rios e as florestas com mercúrio. Pecuaristas estão invadindo e desmatando a fronteira leste de suas terras. A saúde Yanomami está debilitada e serviços médicos essenciais não chegam a eles, especialmente na Venezuela (ELY, 2017).
\end{abstract}

Apesar do tom otimista em muitas destas iniciativas nacionais, o que se tem visto são frentes de expansão do capital penetrando diferentes porções de territórios amazônicos nacionais e deixando mais cicatrizes diversas e profundas que desenvolvimento social ou econômico interno, aprofundando a dependência externa e, sobretudo, da China.

Verificou-se, assim, que as alterações legislativas e direcionamentos públicos evidenciam a deliberada ação dos Estados Nacionais como importantes incentivadores das frentes de capital que penetraram a Gran Amazonía recentemente, bem como revelam a necessidade de promoção de novas articulações e resistências de organizações sociais e populações atingidas ou ameaçadas por muitas dessas iniciativas.

\section{CONSIDERAÇÕES FINAIS}

Viu-se que, após 2000, as formas de expansão do capital se generalizaram na Gran Amaz̧onía. A ascensão da China como grande centro produtor de manufaturas foi seu principal vetor. Na América do Sul, as respostas das políticas econômicas nacionais não foram passivas no front interno, resultando em fortalecimento de políticas sociais e estímulos empresariais. A maior parte das medidas de política econômica, porém, concentraram-se decisivamente nas condições de inserção externa dos países da região. Estes países apostaram nas exportações de commodities como alternativa possível de 
| Expansão do capital e ações dos Estados Nacionais na Gran Amazonía (2000-2019): impactos e impasses |

| Thais Virga | Humberto Miranda do Nascimento |

articulação entre as fontes de crescimento da renda interna e demanda externa, para a retomada do investimento público e dar novo impulso ao crescimento econômico.

Contudo, o subcontinente passou a ser alvo de velhas e novas formas de acumulação e ambição por parte dos grandes capitais nacionais e internacionais (empresas e conglomerados), sem que isso se convertesse, como prometido, em benefícios a seu desenvolvimento. Assim, o processo de reinserção produtiva e reestruturação econômicoespacial na América do Sul encontrou no "controle-uso" do território amazônico problemas, carências e impasses que foram aqui destacados, tanto do ponto de vista dos interesses mais diretamente chineses, quanto da atuação dos Estados nacionais dos países que compões a Gran Amaz̧onía, a fim de responder ao desafio da integração intrarregional.

Chama a atenção o papel dos Estados Nacionais e entes subnacionais ao atuarem, também, como fortes estimuladores da relação "extrazona” na Gran Amazonía. Ou seja, os territórios das amazônias nacionais foram muito tensionados por seus próprios governos em função dos interesses de países de outros continentes, especialmente da China, para mantê-la reproduzindo-se como fronteira de recursos e, em alguns casos, transformá-la em centro de extração mundial de commodities. Assim, suas múltiplas potencialidades naturais ou econômico-comerciais, culturais ou sociais, assim como em termos de segurança e geopolítica regional, ficaram em segundo plano ou foram abandonadas.

Aponta-se, por fim, que os interesses sobre os recursos naturais presentes na Gran Amazonía foram postos em marcha por inúmeros projetos questionáveis na região. Tais projetos foram articulados e incentivados pelos Estados Nacionais, para responder a uma estratégia de desenvolvimento, no mínimo, controvertida. Por esse motivo, mais que outros, as frentes de expansão do capital se favoreceram da intervenção econômica e política na Gran Amazonía, fruto de incentivos, disposições legais e fiscais desses próprios Estados. Em contrapartida, exigências ou estratégias soberanas voltadas, de fato, ao desenvolvimento amazônico pouco prosperaram. Em síntese, essas políticas contribuíram para elevar a insegurança socioambiental e para converter o prometido desenvolvimento em frentes neoextrativistas.

\section{REFERÊNCIAS}

AMAYO ZEVALLOS, E. ¿Por qué estudiar la formación histórica y la problemática actual de la Amazonia? Espiral - Estudios sobre Estado y Sociedad, Guadalajara - México, v. 5, n. 15, p. 73-105, 1999.

BECKER, B. Desafios e perspectivas da integração regional da Amazônia Sul-americana. Parcerias Estratégicas (CGEE), Brasília-DF, p. 25-44, jan./jun. 2010. 
| Expansão do capital e ações dos Estados Nacionais na Gran Amazonía (2000-2019): impactos e impasses |

|Thais Virga | Humberto Miranda do Nascimento |

ÀRIAS, J. A. Los Waorani contra las petroleras en la Amazonia de Ecuador. Jornal Cambio16, Madri - Espanha, Actualidad, Video News, Vídeos, 25 mayo 2019. Disponível em: <https://www.cambio16.com/los-waorani-contra-las-petroleras-en-la-amazonia-deecuador/>. Acesso em: 12 marzo 2020.

BOJÓRQUEZ, O. G. Proyecto minero Río Blanco: una bomba de tiempo en la frontera norte. Servindi, Lima - Perú, 31 agosto 2014. Disponível em: $<$ https://www.servindi.org/actualidad/112397>. Acesso em: 10 marzo, 2020.

CAMPELLO, D.; ZUCCO, C. Presidential Success and the World Economy. The Journal of Politics, v. 78, n. 2, p. 589-602, 29 dec. 2015. Disponível em: <http://dx.doi.org/10.1086/684749>. Acesso em: 28 sept. 2020.

CENTRO DE ESTUDIOS PARA EL DESARROLLO LABORAL Y AGRARIO (CEDLA). Todo o sítio. Disponível em: <https://cedla.org/>. Acesso em: 04 marzo 2020.

COMISSÃO ECONÔMICA PARA A AMÉRICA LATINA E O CARIBE (CEPAL). América Latina y el Caribe y China: hacia una nueva era de cooperación económica. S.15-00389, Nações Unidas (ONU). Santiago - Chile, mayo de 2015.

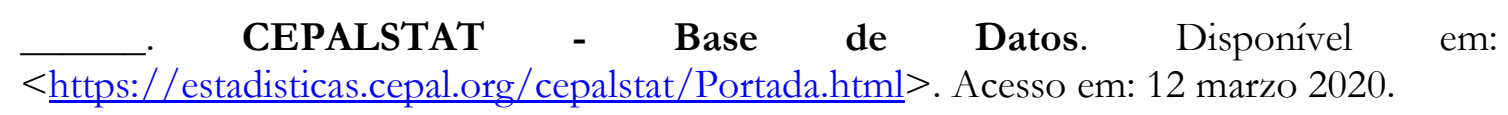

COLECTIVO SOBRE FINANCIAMIENTO E INVERSIONES CHINAS, DERECHOS HUMANOS Y AMBIENTE (CICDHA). Todo o sítio. Disponível em: $<$ http://chinaambienteyderechos.lat/>. Acesso em: 10 marzo 2020.

COSTA, C. Destrucción del Amazonas: las principales amenazas para la mayor selva tropical del mundo en los 9 países que la comparten. BBC News Mundo, 18 feb. 2020. Disponível em: <https://www.bbc.com/mundo/noticias-america-latina-51377234>. Acesso em: 22 feb. 2020.

COSTA, F. de A. Elementos para uma economia política da Amazônia: historicidade, territorialidade, diversidade, sustentabilidade. Belém: NAEA, 2012.

DOUROJEANNI, M. J. Amazonía ¿Qué hacer? Iquitos - Perú: Centro de Estudios Teológicos de la Amazonía (CETA), 1990. 444 p.

ELBEIN, S. De concreto e corrupção: Resistência mata o rio Amazonas nos Andes. Mongabay, 26 jun. 2019. Disponível em: < https://brasil.mongabay.com/2019/06/deconcreto-e-corrupcao-resistencia-mata-o-rio-amazonas-nos-andes/>. Acesso em: $18 \mathrm{fev}$. 2020.

ELY, L. Exploração e mineração na Amazônia venezuelana. Revista IHU On-Line, São Leopoldo - RS, 03 out. 2017. Disponível em: < http://www.ihu.unisinos.br/78noticias/572251-exploracao-e-mineracao-na-amazonia-venezuelana $>$. Acesso em: 12 mar. 2020.

ERTEN, B.; OCAMPO, J. A. Super cycles of commodity prices since the mid-nineteenth century. World Development, Elsevier, v. 44(C), p. 14-30, 2013. 
| Expansão do capital e ações dos Estados Nacionais na Gran Amazonía (2000-2019): impactos e impasses |

| Thais Virga | Humberto Miranda do Nascimento |

FELIPE, S. Negócios da China: Como a grana da China desaloja. The Intercept Brasil, Rio de Janeiro, 17 fev. 2020. Disponível em: $<$ https://theintercept.com/2020/02/17/governo-flavio-dino-china-maranhao/>. Acesso em: 10 mar. 2020.

FRIAS, A.F.; MAIDA, F.; MAIDA, J.P. Política Ambiental e Sustentabilidade. EcoDebate, 29 jun. $2016 . \quad$ Disponível em: $<$ https://www.ecodebate.com.br/2016/09/29/politica-ambiental-e-sustentabilidade-umclamor-da-sociedade-pela-modernidade-e-inovacao-na-regulamentacao-para-a-atividade-demineracao-por-aparecida-ferreira-frias-fernando-maida-e-joao-paulo-maida/>. Acesso em: 02 abr. 2020.

GARCÍA, A. (2007). El Síndrome del Perro del Hortelano. El Comercio, Lima - Perú, 28 oct. 2007. Disponível em: <http://peruesmas.com/biblioteca-jorge/Alan-Garcia-Perez-yel-perro-del-hortelano.pdf>. Acesso em: 10 enero 2020.

INSTITUTO DO HOMEM E MEIO AMBIENTE DA AMAZÔNIA (IMAZON). O Estado da Amazônia: uso da terra. Belém, 2015. Disponível em: $<$ https://imazon.org.br/o-estado-da-amazonia-uso-da-terra/>. Acesso em: 12 dez. 2019.

INVERSIONES CHINAS EN AMÉRICA LATINA. Todo o sítio. Disponível em: <https://www.chinaenamericalatina.info/principal/>. Acesso em: 27 feb. 2020.

JEMIO, M. T. Bolívia comemora exportação de carne à China, mas teme desmatamento. Dialogo Chino, 5 jul. 2019. Disponível em: < https://dialogochino.net/pt-br/agriculturapt-br/28326-bolivia-comemora-exportacao-de-carne-a-china-mas-teme-desmatamento/>.

Acesso em: 12 fev. 2020.

MANZI, R. H. D. O fim do superciclo das commodities internacionais e seus reflexos na economia brasileira. Conjuntura internacional, Belo Horizonte, PUC-Minas, v. 13, n. 1, p. 36-43, 2016.

MEDEIROS, C. A.; CINTRA, M. R. V. P. Impacto da ascensão chinesa sobre os países latino-americanos. Brazilian Journal of Political Economy, v. 35, n. 1, p. 28-42, 2015.

MORENO, C. O Brasil made in China: para pensar as reconfigurações do capitalismo contemporâneo. São Paulo: Fundação Rosa Luxemburgo, 2015.

NEHER, C.; PONTES, N. Negócio da China na Amazônia Equatoriana. DW Brasil, 05

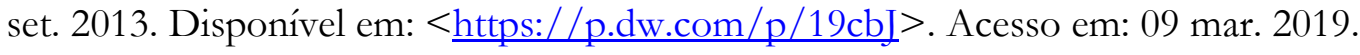

PALMA, J. Ecuador: comunidad amazónica denuncia escasez de peces y culpa a la mayor hidroeléctrica construida en el país. Mongabay, 01 jun. 2017. Disponível em: $<$ https://es.mongabay.com/2017/06/hidroelectricas-pueblos indigenas-conflictos-riosecuador/>. Acesso em: 10 marzo 2020.

REDE AMAZÔNICA DE INFORMAÇÃO GEORREFERENCIADA (RAISG). Amazonia bajo presion, São Paulo: ISA - Instituto Socioambiental, 2020.

VIRGA, T. Integração física e desenvolvimento na América do Sul: transformações e prospectivas da infraestrutura de transportes na região do "Eixo Amazonas" na Amazônia 
| Expansão do capital e ações dos Estados Nacionais na Gran Amazonía (2000-2019): impactos e impasses |

|Thais Virga | Humberto Miranda do Nascimento |

Centro-Ocidental (2000-2018). 2019. 594 p. Tese (Doutorado em Desenvolvimento Econômico) - Universidade Estadual de Campinas, Campinas, 2019.

VOGLIANO, S. Ecuador - Extracción petrolera en la Amazonia: conflictos socioecológicos. Ecuador, Fundación Hogar del Empleado (FUHEM), Ficha No 12, 2009. Disponível

em: <https://www.fuhem.es/media/ecosocial/image/culturambiente/fichas/ECUADOR co mbustibles n22.pdf $>$. Acesso em: 13 marzo 2020.

WORLD BANK. The World Integrated Trade Solution (WITS). Trade Stats. Disponível em: <https://wits.worldbank.org/CountryProfile/Metadata/en/Country/All>. Acesso em: 28 dez. 2020.

YOUKEE, M. (2019). China amplia sua influência na Guiana. Dialogo Chino, 28 jan. 2019. Disponível em: < $\underline{\text { https://dialogochino.net/pt-br/infraestrutura-pt-br/21419-china- }}$ amplia-sua-influencia-na-guiana/>. Acesso em: 17 maio 2020.

\title{
Como citar este artigo:
}

\begin{abstract}
ABNT
VIRGA, T.; NASCIMENTO, H. M. Expansão do capital e ações dos Estados Nacionais na Gran Amazonía (2000-2019): impactos e impasses. InterEspaço: Revista de Geografia e Interdisciplinaridade, v. 7, e202101, 2021. Disponível em: <http://dx.doi.org/10.18764/2446-6549.e202101>. Acesso em: 24 mar. 2021.
\end{abstract}

\section{APA:}

Virga, T. \& Nascimento, H. M. Expansão do capital e ações dos Estados Nacionais na Gran Amazonía (2000-2019): impactos e impasses. InterEspaco: Revista de Geografia e Interdisciplinaridade, v. 7, e202101. Recuperado em 24 março, 2021, de http://dx.doi.org/10.18764/2446-6549.e202101

\section{@creative}

This is an open access article under the CC BY Creative Commons 4.0 license.

Copyright (C) 2021, Universidade Federal do Maranhão.

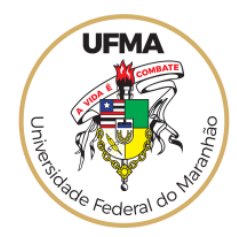

